\title{
last word
}

\section{Do It Yourself dentistry}

\section{Earlier in the year a pensioner was reported to have taken out her teeth because she couldn't find a dentist. So just what are the advantages of}

DIY dentistry? Stephen Hancocks opens a dental flat pack.

W

e're all so familiar with the scenario that it is almost painful to repeat it.

The enticing thing about DIY is that it seems like such a good solution - at the time. It has the allure of being economic (cheap), easy to organise (you don't have to find anyone else to do it) and convenient (no valuable time off work). But for those of us who have ever tried it, we know that it just isn't that straightforward. The trouble is that we forget, between times, what a nightmare it can be.

Take, for example, those three words that should never knowingly be placed in a row together 'easy to assemble'. Whatever piece of furniture or equipment is involved, it invariably looks so good in the showroom or catalogue, surrounded by colourful rugs, swatches of material and other already assembled pieces, it steals your heart and says 'buy me, buy me'. So you do.

Surprised that such a flat pack can weigh so much, especially if you're taking it home on the bus, you eventually lug it into the appointed room or space and stand looking at it with some sudden pangs of doubt. The box is opened and the pieces carefully checked against the inventory which is printed in slightly bad English, ('the joining piece for the fronts and backnesses'), the screws are counted and the strange little wooden plugs lined up as shown in the diagram. But therein lays the start of the headache. Which way up is the plan supposed to be, and why doesn't that wretched joining piece actually reach across between the two other components?

Then there is the step further for the really adventurous, choosing your own materials and really going it alone. This will mean a trip to the DIY store, or for those with real confidence the old fashioned hardware shop. Surrounded by shelves, racks, boxes and trays of every imaginable 'thingy' in metal, wood, and plastic you might be lucky enough to be served by one of the dying breed of men in brown warehouse coats with a row of ball point pens in their breast pocket.

In triumph you arrive home with a crumpled paper bag full of fascinating parts only to find that the sizes are just that bit too large, small, long, short, with the incorrect thread or just plainly the wrong bits. Alas, you always discover this at the time that the shop has closed by five minutes and, since it's a Bank Holiday, will not now be open again until you're back at work.

Of course all of these horrors might easily be repeated in the practice setting and don't think that it couldn't come to it. Probably blessed with an obscure Scandinavian name, the Kremefjord Self Assemble Dental Surgery could well be in a store near you soon. What fun to discover that the screw that's missing is the one that holds the headrest on the chair, or that the two spare bits of black plastic that you couldn't find a place to fit and so threw away are now causing a nasty smell to evaporate from the spittoon.

And if all that doesn't bear thinking about, what price the possibility of DIY clinical dentistry? An easy to assemble crown and bridge kit for example, or a home use implant outfit complete with local anaesthetic, twist drill set (with self-tapping screws) and easy fit sutures? Of course it couldn't happen - could it? Not in the UK because only dental professionals can carry out the 'practice of dentistry'. But what if you decided to DIY it outside territorial waters or up a mountain in the Himalayas? Surely the GDC couldn't pursue you there? Except presumably it would be tough enough trying to fit your own veneers with a mirror, tweezers and tube of superglue without the added hazards of a force seven gale, ten foot waves or a lack of oxygen at 16,000 feet.

The answer seems to be, sadly, if you want a job done properly... ask an expert, especially where dentistry is concerned.

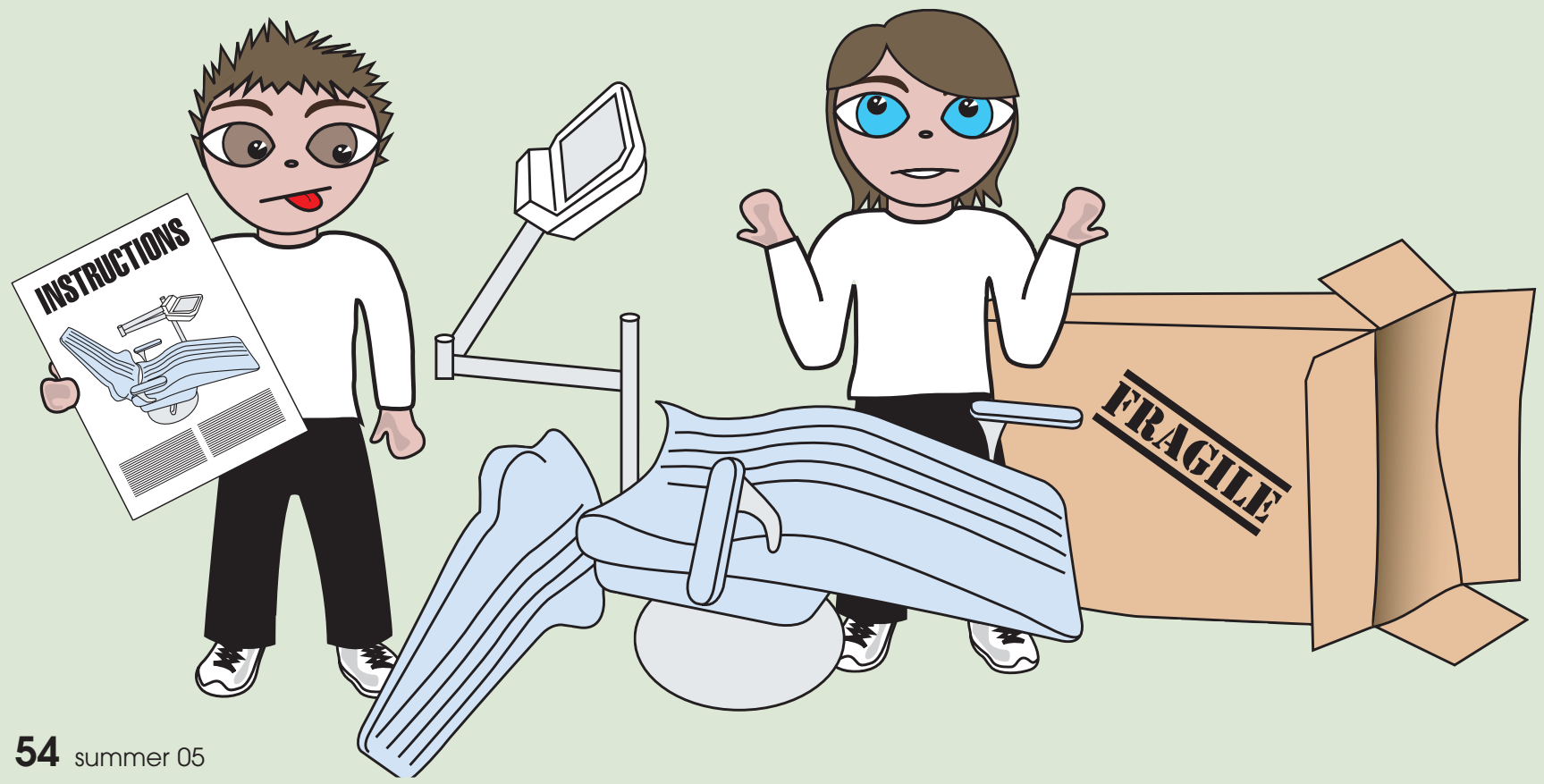

